\title{
Atividade de Situações Problema Discente com operações de adição e subtração
}

Resumo: Compreender a importância de resolver problemas na vida cotidiana, é uma ação que necessita ter vínculos a propostas expressivas, com procedimentos metodológicos que surtam efeito no ensino e na aprendizagem. O objetivo do artigo é analisar as contribuições da Atividade de Situações Problema Discente com as operações de adição e subtração dos discentes do $3^{\circ}$ ano do Ensino Fundamental do Colégio de Aplicação da UFRR. O trabalho está fundamentado na teoria da atividade na perspectiva dos autores Galperin, Talízina e Majmutov. A realização da pesquisa ocorreu por meio de abordagem qualitativa; a análise dos dados realizou-se considerando o diagnóstico inicial e as avaliações formativa e final, a partir de critérios preestabelecidos. Os resultados mostraram transformações qualitativas na aprendizagem dos discentes em relação a resolução de problemas com adição e subtração.

Palavras-chave: Ensino Problematizador de Majmutov. Teoria da Atividade. Teoria de GalperinTalízina. Matemática no Ensino Fundamental. Resolução de Problemas.

\section{Student Problem Situations Activity with addition and subtraction operations}

Abstract: Understanding the importance of problem solving in everyday life is an action that must be linked to expressive proposals, with methodological procedures that improve teaching and learning. The objective of the article is to analyze the contributions of the Student Problem Situations Activity with addition and subtraction operations in 3rd grade students of the UFRR School of Application. The work is based on activity theory from the perspective of authors Galperin, Talízina and Majmutov. The research was carried out through a qualitative approach. The data analysis was carried out considering the initial diagnosis and the formative and final evaluations, based on pre-established criteria. The results showed qualitative changes in students' learning in relation to problem solving with addition and subtraction.

Keywords: Majmutov's Problematic Teaching. Activity Theory. Galperin and Talízina Theory. Mathematics in Elementary School. Solving Problems.

\section{Actividad de Situaciones Problema del Estudiante con}




\section{operaciones de suma y resta}

Resumen: Comprender la importancia de la resolución de problemas en la vida cotidiana es una acción que debe estar vinculada a propuestas expresivas, con procedimientos metodológicos que mejoren la enseñanza y el aprendizaje. El objetivo del artículo es analizar las contribuciones de la Actividad Situaciones Problema del Estudiante con operaciones de suma y resta en estudiantes del $3^{\circ}$ grado del Colegio de Aplicación de la UFRR. El trabajo se fundamenta en la teoría de la actividad desde la perspectiva de los autores Galperin, Talízina y Majmutov. La investigación fue realizada a través de un enfoque cualitativo. El análisis de los datos se realizó considerando el diagnóstico inicial y las evaluaciones formativas y finales, con base en criterios preestablecidos. Los resultados mostraron cambios cualitativos en el aprendizaje de los estudiantes en relación con la resolución de problemas con sumas y restas.

Palabra clave: Enseñanza Problemática de Majmutov. Teoría de la Actividad. Teoría de Galperin y Talízina. Matemática en la Enseñanza Primaria. Resolución de Problemas.

\section{Introdução}

Um dos objetivos fundamentais da prática pedagógica é a aprendizagem dos discentes. Compreender de forma ampla o conceito de aprender torna-se essencial para a construção do conhecimento como uma atividade contínua que se inicia ao nascimento e perdura por toda vida. Esta pesquisa foi realizada no âmbito do Mestrado em Educação da Universidade Estadual de Roraima (UERR) e apresenta os resultados alcançados com as análises dos dados levantados de forma consolidada.

De acordo com Delgado e Mendoza (2016), à medida que as ações dependem do conhecimento adquirido, é inevitável questionar as condições necessárias para que a aprendizagem ocorra de maneira efetiva, levando-se em consideração a escola como um dos ambientes onde é possível disseminar os conhecimentos e onde o professor deve assumir a atribuição de possibilitar para os discentes a expansão de suas aprendizagens. Assim, é provável que estes desenvolvam capacidades internas com mais autonomia sobre o seu processo de aprender.

A ação educativa organizada oportuniza ao discente avançar na aprendizagem e no desenvolvimento. Esta pode ser realizada de modo individual ou com ajuda de outra pessoa por um determinado período, até consegui-lo fazer sozinho. Contudo, é papel da escola definir metas que garantam a aprendizagem, uma vez que todos têm a capacidade de aprender e avançar nas etapas de apropriação do conhecimento. Nessa perspectiva, estudos na Teoria Histórico-Cultural, como os de Vygotsky (2003), do Ensino 
Problematizador de Majmutov (1983), da Teoria da Direção da Atividade de Estudo de Talízina (1988) e da Teoria de Formação por Etapas das Ações Mentais de Galperin (1979) têm se destacado em várias pesquisas na área de Matemática com notáveis contribuições para os processos de ensino e de aprendizagem.

A partir dos fundamentos desses autores e direcionado pelos estudos de Mendoza (2009), o presente artigo trata da Atividade de Situações Problema Discente como um conjunto de procedimentos metodológicos a partir da resolução de problema, pautados em ações e operações que orientam o desenvolvimento do planejamento do professor, visando potencializar as habilidades dos discentes. Este tem por objetivo analisar as contribuições da Atividade de Situações Problema Discente (ASPD) fundamentada na teoria de Galperin, Talízina e Majmutov para formação de habilidade na resolução de problema com operações de adição e subtração nos discentes do $3^{\circ}$ ano do Ensino Fundamental do Colégio de Aplicação da Universidade Federal de Roraima (CAp/UFRR). Com isso, o desenvolvimento da ASPD ocorreu com base em tarefas de caráter problematizador com vistas a garantir a aprendizagem dos discentes.

É importante destacar que o professor participa ativamente no processo de construção da aprendizagem dos discentes, quando este apresenta tarefas planejadas e organizadas pautadas em teorias que fundamentam o ensino, este deve estar atento às possibilidades de solução utilizadas pelos discentes que poderão ir além de procedimentos tradicionais. Outros meios poderão ser utilizados de acordo com a estratégia adotada por cada um, fazendo uso de recursos didáticos ou não, pois para resolver situações do dia a dia é possível que eles não utilizem o algoritmo habitual com o uso de lápis e papel, suas estratégias dependerão da necessidade de resolver os problemas. Para que o raciocínio aditivo e subtrativo seja entendido, é necessário que percebam que a adição é o inverso da subtração e vice-versa. Assim, foi possível utilizar conhecimentos e habilidades matemáticas viáveis para solucionar situações-problema da prática cotidiana.

No caminho a percorrer para que o objetivo seja alcançado, considerou-se os procedimentos metodológicos como uma pesquisa de cunho qualitativo desenvolvida com uma turma de $3^{\circ}$ ano do Ensino Fundamental, do Colégio de Aplicação CAp/UFRR, localizado na cidade de Boa Vista - RR. Foram coletados dados a partir da aplicação do diagnóstico inicial e das avaliações formativa e final para afirmação das informações levantadas, de modo a dar suporte na análise e discussão dos dados afim de 
viabilizar a compreensão do processo, sistematizar, teorizar, quantificar e qualificar os dados obtidos. Dessa maneira, este artigo se justifica por colaborar com a disseminação da utilização de situações-problema como procedimentos metodológicos para a aprendizagem dos discentes e espera-se contribuir na melhoria da prática docente.

Nesta perspectiva acredita-se que a pesquisa poderá contribuir para expandir o debate sobre as possibilidades de aprendizagem e autonomia dos discentes, considerando a proposta da ASPD por meio da resolução de problema para a formação de habilidades nos discentes do $3^{\circ}$ ano. Dessa maneira, este artigo se justifica por colaborar com a disseminação da utilização de situações-problema como estratégia metodológica para a aprendizagem dos discentes e espera-se contribuir na melhoria da prática docente.

\section{A Teoria da Atividade}

Os estudos propostos por Vygotsky (2003), por meio da Teoria HistóricoCultural, apontam que uma atividade mediada proporciona a construção dos processos mentais superiores e regula a ação do discente sobre os objetos externos. A Zona de Desenvolvimento Proximal é o conceito fundamental dessa teoria; busca compreender como o desenvolvimento e a aprendizagem dos discentes ocorre e, ainda, analisar como acontece essa relação nos processos de ensino e de aprendizagem como uma questão primordial. Com isso, o ensino organizado passa a ter grande importância, pois constitui significados para a evolução do indivíduo e favorece a estruturação do conhecimento pelos discentes.

Por conseguinte, conforme destaco em Mendoza e Delgado (2018), o papel do professor frente a proposta de contribuir para o desenvolvimento intelectual do discente é de fundamental importância, pois a definição do que ensinar e como propor as atividades fará a diferença nos resultados que se espera alcançar. Associado às contribuições apresentadas por Vygotsky, tem-se o ensino problematizador fundamentado por Majmutov (1983), que ressalta o ensino como a ligação com a independência cognitiva do discente e um dos fatores de estímulo ao desenvolvimento de suas capacidades criativas. Para o autor, o ensino problematizador é o meio que proporcionará uma aprendizagem efetiva por meio das soluções das contradições presentes nas tarefas.

Ao interagir com os colegas, os discentes têm a oportunidade de manifestar suas 
suposições, compará-las e defendê-las de modo que consiga argumentar e absorver as especificidades do objeto de estudo. O ensino problematizador é a via de acesso para essa aprendizagem, pois a lógica dialética é constituída pelo reflexo e pela solução das contradições que as tarefas trarão que, de acordo com Majmutov (1983, p. 125), "a base da atividade mental do homem é a situação problêmica". Dessa forma, os discentes aprenderão os significados ao longo do tempo, desde que sejam criadas oportunidades para que estes façam descobertas. Com isso, é necessário propor tarefas desafiadoras para que estes se sintam estimulados a resolvê-las. Majmutov (1983, p. 129) conceitua problema discente como

fenômeno subjetivo que existe na consciência do aluno em sua forma ideal, no pensamento, do mesmo modo que qualquer julgamento, enquanto, logicamente, não seja aperfeiçoado e expresso (sob a forma de oração) através dos sons da linguagem ou nos sinais escritos.

Sendo assim, problema discente é a contradição do pensamento lógico e psicológico no processo de assimilação, é a busca pela solução por meio de sua representação linguística, a tarefa. Que por sua vez, tarefa é um fenômeno objetivo, pois para o discente existe desde o início na sua forma material (em sons ou sinais) e se transforma em subjetivo somente após ter percepção e conscientização disso (MAJMUTOV, 1983).

Nesta perspectiva, as ações docentes precisam considerar os saberes dos discentes para adequar o planejamento didático, na intenção de favorecer a aprendizagem. Esta acontece em todo lugar e a todo instante, sendo importante a convivência dos discentes com os saberes diversos que os rodeiam, para que apreendam os significados e construam o seu aprendizado, necessitando, para isso, do intermédio de uma pessoa adulta - no caso da escola, o professor - ou, ainda, da interação com colegas que possuam o conhecimento em um nível maior, até terem internalizado o objeto de estudo.

Ao tratar sobre a atividade a pesquisa abordou o enfoque dado por Leontiev (1978) que explica que o conceito de atividade é caracterizado pelos processos psicológicos superiores e seu objeto de investigação, sendo a relação do ser humano com o mundo conduzido por princípios e objetivos, com planejamento organizado passando a ser direcionado por um processo sócio-histórico. A atividade é, pois, uma forma de interação do indivíduo com o mundo, a ligação para o entendimento de suas ações, visto que 
desencadeará mudanças psíquicas no momento de sua realização. Portanto, para que o propósito seja alcançado, o professor não poderá escolher qualquer atividade, esta necessita de critérios sistematizados, que no caso da pesquisa são as ações e operações definidas na ASPD, para que atinja o objetivo final.

Considerando o conceito de atividade elaborado por Leontiev (1978), Galperin (1979), ao estabelecer a Teoria das Etapas de Formação das Ações Mentais, as estruturou de forma a dar consistência ao tipo de atividade a ser utilizada e as etapas que deverão ser observadas e desenvolvidas até a aprendizagem. Essas etapas são um conjunto de procedimentos que objetivam contribuir com o aprendizado dos discentes, visto que cada ação é composta de operações que conduzem para a compreensão e para obtenção do objetivo proposto. Pois, para que os discentes aprendam devem ter ações organizadas que os levem a realizar, primeiramente, as ações de forma externa para depois serem internalizadas e automatizadas.

Como contribuição a essas discussões Talízina (1988, p. 23) salienta que "o motivo da atividade é interpretado não só como uma necessidade do sujeito, mas uma necessidade objetivada, como o objeto que move o sujeito à ação". Assim, é importante destacar que o conceito de atividade tem estreita relação ao conceito de consciência, pois o ser humano se difere dos demais justamente porque antes de realizar ações ele tem a inteligência de planejá-las e organizá-las mentalmente, em conformidade ao objetivo proposto. Para Gonçalves e Núñez (2017), o grande diferencial na direção das ações é que a "orientação do sujeito norteia a execução de sua ação em uma nova situaçãoproblema e ainda se coloca como o referencial para o controle dessa ação" (p. 280), os discentes podem ser estimulados quando se propõe situações desafiadoras.

As ações ao serem definidas assumem dentro do contexto de aprendizagem uma função específica. Talízina (1988) considera que a Base Orientadora da Ação (BOA) é uma representação da ação a ser executada e suas condições para a realização. A autora define as ações com três funções específicas, sendo elas: a de orientação, que deve ser aquela que está centrada nas condições dadas aos discentes para que eles realizem com êxito o propósito da aprendizagem; a de execução, os discentes devem efetuar a ação solicitada recorrendo à apropriação do objeto de estudo; e a de controle, que cabe ao professor e aos discentes acompanhar se a ação foi realizada com sucesso, ou ainda, 
perceber possíveis falhas no decorrer de sua resolução, viabilizando, quando necessário, formas de reorganização na parte orientadora ou na parte executora, quando o resultado não estiver correto.

Em pesquisas realizadas sobre a teoria de Galperin, Talízina (1988) argumenta que o estudo é um conjunto de atividades que propicia oportunidades com o objetivo de aprender algo e a aquisição de novas habilidades. É possível a realização dessas atividades, desde que os discentes cumpram o objetivo proposto, que por sua vez implica está disposto a aprender, ou seja, necessita ter motivação. Às Etapas de Formação das Ações Mentais foi acrescentada a Etapa Motivacional. Para Talízina (2009, p. 41) "sabese que se alguém não quer aprender não se lhe pode ensinar nada". Apenas ter motivação para aprender não é suficiente para que se conceba uma aprendizagem efetiva, muito embora, sem ela os processos de ensinos e de aprendizagem ficam prejudicados. A motivação para a aprendizagem deve ser promovida de forma que torne os discentes ativos e preparados para a assimilação de novos conhecimentos.

Com isso, para conceituar a Teoria de Galperin, Núñez e Ramalho (2017), descrevem as Etapas (E) que a compõe: a Etapa motivacional, é o início do processo, deve ser mantido durante todo o seu desenvolvimento; a BOA, corresponde à etapa de orientação, a Forma material ou materializada, corresponde à utilização de objetos reais ou sua representação; a Ação verbal externa é quando a ação se realiza usando recursos da linguagem externa (oral ou escrita), sem apoio em objetos materiais ou materializados; a Linguagem externa para si, surge quando não há necessidade de objetos reais ou suas representações, eles podem ser substituídos pelo uso da linguagem externa ou pelo pensamento; e, por fim, a Linguagem interna, que é quando os discentes abreviam as operações da ação, realizando-as com maior rapidez. Ao se transformar num fenômeno do pensamento, a ação pode ser realizada numa nova forma: a mental.

Depois de passado por todas essas etapas de formação mental a aprendizagem está automatizada. Delgado e Mendoza (2016, p. 366) concluem que "na internalização do objeto de estudo (conteúdos) consiste a transformação das ações: externas em internas, materiais em mentais, não generalizada em generalizada, detalhadas em comprimidas, conscientes em automatizadas, compartilhadas em abreviadas". Para tanto, o desenvolvimento das etapas de aprendizagem deve estimular a autoestima dos discentes e o professor precisa deixar explícito suas expectativas ao observá-los durante o processo 
de resolução, levando-os a justificar e avaliar os resultados e métodos, e por fim, formalizar novos conceitos construídos.

\section{Fundamentos didáticos para a aprendizagem}

A Base Nacional Comum Curricular (BNCC) indica como sugestão que o professor coloque os discentes diante de situações em que "desenvolvam a capacidade de identificar oportunidades de utilização da Matemática para resolver problemas, aplicando conceitos, procedimentos e resultados para obter soluções e interpretá-las segundo os contextos das situações" (BRASIL, 2017, p. 265). Outrossim, é necessário considerar os elementos para o desenvolvimento das tarefas que levem ao sucesso na aprendizagem, tais como: a motivação, a ação, as operações, os objetivos, as habilidades e, por conseguinte, os resultados. Para colaborar com essa discussão Bueno, Alencar e Millones (2017, p. 15) destacam que "a resolução de situações-problema propicia a interação entre o professor e os alunos quebrando a rotina da sala de aula e contribui para o ensino de conceitos matemáticos tornando a aprendizagem do aluno mais significativa".

É importante trabalhar a resolução de problema na escola de modo que estimule e valorize as formas de calcular de cada discente e os possibilite desenvolver a agilidade e a incidência de menos erros, por meio de uma construção sólida de procedimentos escritos e/ou mentais. Assim, o ensino e a aprendizagem estarão organizados de acordo com o seu conhecimento e aos poucos irá se transformando de ação externa para interna, isto é, de ação material para mental. Para Van de Walle (2009) é necessário que os discentes correlacionem diversas interpretações entre as operações aritméticas de forma que as utilize de maneira viva em suas vidas diárias. O autor aponta que, para resolver uma situação-problema que envolve as operações, o professor precisa conhecer as estruturas que as cercam e a partir de então desenvolver o trabalho com os discentes. Cabe ao professor planejar ações que atendam as demandas de forma integrada.

O professor precisa estar atento às possibilidades de solução utilizadas pelos discentes que poderão ir além de procedimentos tradicionais. Outros meios serão utilizados de acordo com a estratégia adotada por cada um, fazendo uso de recursos didáticos ou não, pois para resolver situações do dia a dia é possível que eles não utilizem o algoritmo habitual com o uso de lápis e papel; suas estratégias dependerão da 
necessidade de resolver os problemas utilizando-se do cálculo mental ou, ainda, de recursos materiais ou materializados. Ressalta-se, ainda, a necessidade de extrapolar as atividades sugeridas, de forma que o planejamento esteja organizado com enfoque problematizador, entre as possibilidades pedagógicas vislumbradas a Atividade de Situações Problema Discente deve contribuir nesse contexto.

\section{Atividade de Situações Problema Discente com operações de adição e subtração}

No contexto educacional as discussões se fomentam na perspectiva de relacionar o que os discentes trazem de fora do ambiente escolar e o trabalho com tarefas mais reais, aproveitar o contexto social como instrumento para o seu desenvolvimento. Para que tal concepção surta efeito é necessário que os professores de Matemática entendam como aplicar os conceitos e colocá-los em prática nas aulas, favorecendo meios viáveis para a construção da aprendizagem. Assim, julga-se importante utilizar metodologias que proporcionem o avanço intelectual dos discentes com ações bem planejadas e estruturadas para esse fim.

Evidencia-se que é importante propor, a partir da utilização da ASPD, como serão tratadas as concepções matemáticas na escola e a relação destas com os discentes, de modo que favoreça o respeito às diferenças que existem entre eles, pois ao agir dessa forma estimula-se o despertar para o aprendizado e para o fortalecimento das possibilidades de um ensino com uma metodologia mais interessante e eficaz para todo grupo. Assim, há possibilidades de que os discentes estabeleçam suas estratégias para aprender, criar e recriar seus conhecimentos.

Em Mendoza e Delgado (2020) enfatiza-se que a ASPD é um sistema invariante com quatro ações, com suas respectivas operações que admitem solucionar os mais diversos problemas matemáticos e pode ser utilizada para resolver outros tipos de problema discente, favorecendo maior dinamicidade. Enfatiza-se que a aprendizagem matemática e, por extensão, o desenvolvimento do raciocínio matemático, demandam um trabalho consistente com e entre os diversos campos conceituais por um longo período de forma estruturada, fazendo o professor perceber diferentes formas de encaminhar o desenvolvimento intelectual dos discentes (MENDOZA e DELGADO, 2018). No Quadro 1, são apresentadas as ações e operações gerais da ASPD. 
Quadro 1: Modelo da Ação e de Controle da Atividade de Situações Problema Discente

\begin{tabular}{|c|c|c|}
\hline & Modelo da Ação & Modelo de Controle \\
\hline Ações & Operações das ações & Operações de controle \\
\hline $\begin{array}{l}\text { Formular } \\
\text { problema } \\
\text { discente }\end{array}$ & $\begin{array}{l}\text { O1. Determinar os elementos } \\
\text { conhecidos a partir dos dados e/ou } \\
\text { condições e/ou conceitos e/ou } \\
\text { procedimentos da tarefa. } \\
\text { O2. Definir os elementos } \\
\text { desconhecidos a partir dos dados e/ou } \\
\text { condições e/ou conceitos e/ou } \\
\text { procedimentos da tarefa. } \\
\text { O3. Reconhecer o conhecimento } \\
\text { buscado. }\end{array}$ & $\begin{array}{l}\text { C1. Identificou-se os elementos } \\
\text { conhecidos a partir dos dados e/ou } \\
\text { condições e/ou conceitos e/ou } \\
\text { procedimentos da tarefa? } \\
\text { C2. Definiu-se os elementos } \\
\text { desconhecidos a partir dos dados e/ou } \\
\text { condições e/ou conceitos e/ou } \\
\text { procedimentos da tarefa? } \\
\text { C3. Reconheceu o buscado e/ ou } \\
\text { objetivo? }\end{array}$ \\
\hline $\begin{array}{l}\text { Construir o } \\
\text { núcleo } \\
\text { conceitual e } \\
\text { procedimental }\end{array}$ & $\begin{array}{l}\text { O4. Selecionar os conceitos e } \\
\text { procedimentos conhecidos } \\
\text { necessários para a solução do } \\
\text { problema discente. } \\
\text { O5. Atualizar outros conceitos e } \\
\text { procedimentos conhecidos que } \\
\text { possam estar vinculados com os } \\
\text { desconhecidos. } \\
\text { O6. Encontrar estratégia(s) de } \\
\text { conexão entre os conceitos e } \\
\text { procedimentos conhecidos e } \\
\text { desconhecidos. }\end{array}$ & $\begin{array}{l}\text { C4. Selecionou os conceitos e } \\
\text { procedimentos conhecidos } \\
\text { necessários para a solução do } \\
\text { problema discente? } \\
\text { C5. Atualizou-se outros conceitos e } \\
\text { procedimentos conhecidos que } \\
\text { possam estar vinculados com os } \\
\text { desconhecidos? } \\
\text { C6. Encontrou-se uma estratégia de } \\
\text { conexão entre os conceitos e } \\
\text { procedimentos conhecidos e } \\
\text { desconhecidos? }\end{array}$ \\
\hline $\begin{array}{c}\text { Solucionar o } \\
\text { problema } \\
\text { discente }\end{array}$ & $\begin{array}{l}\text { O7. Aplicar a(s) estratégia(s) para } \\
\text { relacionar os procedimentos } \\
\text { conhecidos e desconhecidos. } \\
\text { O8. Determinar o conhecimento } \\
\text { buscado e/ou objetivo. }\end{array}$ & $\begin{array}{l}\text { C7. Aplicou corretamente a(s) } \\
\text { estratégia(s) de solução para } \\
\text { relacionar os procedimentos } \\
\text { conhecidos e desconhecidos? } \\
\text { C8. Determinou o buscado e/ou } \\
\text { objetivo? }\end{array}$ \\
\hline $\begin{array}{l}\text { Analisar a } \\
\text { solução }\end{array}$ & $\begin{array}{l}\text { O9. Verificar se a solução } \\
\text { corresponde com objetivo e as } \\
\text { condições do problema discente. } \\
\text { O10. Verificar se existem outras } \\
\text { maneiras de resolver o problema } \\
\text { discente a partir do conhecido } \\
\text { atualizado com o desconhecido. } \\
\text { O11. Verificar se solução é } \\
\text { coerente com dados e condições do } \\
\text { problema. }\end{array}$ & $\begin{array}{l}\text { C9. Verificou-se a solução } \\
\text { corresponde com objetivo e as } \\
\text { condições do problema discente? } \\
\text { C10. Verificou-se existem outras } \\
\text { maneiras de resolver o problema } \\
\text { discente a partir do conhecido } \\
\text { atualizado com o desconhecido? } \\
\text { C11. Verificou-se solução é coerente } \\
\text { com dados e condições do problema? }\end{array}$ \\
\hline
\end{tabular}

Fonte: Mendoza e Delgado (2020, p. 193)

Assim, as ações e operações desempenham um papel fundamental no processo de formação de uma habilidade, que é a de levar os discentes a orientar-se em relação às 
condições e procedimentos para execução da tarefa, colocando-as em prática por meio da realização das operações. Essa organização propicia a orientação e o controle da habilidade a ser desenvolvida e ocorre a medida em que se desenvolve o processo de solução das tarefas. Conforme destacado em Feitosa (2014, p. 28), "resolver problemas é construir meios para encontrar respostas, ou seja, realizar ações e operações para obter resultado", organizar o ensino é uma das primeiras ações a serem definidas.

Partindo-se dessa premissa, com os estudos teóricos realizados a partir das leituras de Majmutov (1983), Talízina (1988), Galperin (1979), Mendoza (2009), Delgado e Mendonza (2016) e Mendoza e Delgado (2018 e 2020) seguindo a linha teórica apontada na pesquisa, colocou em discussão o ensino da Matemática alicerçado na aplicação da Atividade de Situações Problema Discente com operações de adição e subtração, aplicada no $3^{\circ}$ ano do Ensino Fundamental do CAp/UFRR, com o intuito de analisar as possibilidades de contribuição da ASPD em relação às habilidades na resolução de problema que envolvem essas operações.

\section{Sequência didática}

O planejamento de ensino caracteriza-se como a organização de um roteiro de ações didáticas a serem desenvolvidas com os discentes a partir dos resultados do diagnóstico inicial. Deve-se traçar os objetivos a serem alcançados, conteúdos, metodologia e avaliação associando estes elementos aos princípios básicos da teoria aplicada. Conforme discutido em Mendoza e Delgado (2016), a sequência didática da ASPD, com base na teoria de Galperin, favorece a eficiência do processo de aprendizagem dos discentes que ficam melhor preparados para resolver o maior número de situações. Com isso, fica estabelecido uma previsão das ações docentes de modo a evitar improvisos, possibilitando ao professor a realização de um ensino direcionado, para que viabilize a aprendizagem dos discentes.

A sequência didática, seguindo as Etapas de Formação das Ações Mentais de Galperin e na perspectiva do Ensino Problematizador de Majmutov, foi elaborada a partir das análises dos resultados do diagnóstico inicial. Objetivou estabelecer estratégias educacionais de melhoria no aprendizado dos discentes, numa sequência evolutiva, buscando ampliar o conhecimento e engajamento destes nos processos de ensino e de aprendizagem. O planejamento da sequência didática trouxe adaptações para orientar e 
apoiar os discentes; baseou-se em ações essenciais para a internalização dos conceitos de adição e subtração com a realização das tarefas de forma efetiva. Apresenta-se a sequência didática no Quadro 2.

Quadro 2: Sequência didática da ASPD com operações de adição e subtração

\section{Sequência Didática da Atividade de Situação Problema Discente com Operações de Adição e Subtração}

\section{Habilidades}

(EF03MA05) Utilizar diferentes procedimentos de cálculo mental e escrito, inclusive os convencionais, para resolver problemas significativos envolvendo adição e subtração com números naturais.

(EF03MA06) Resolver e elaborar problemas de adição e subtração com os significados de reunir, acrescentar, separar, retirar, comparar e completar quantidades, utilizando diferentes estratégias de cálculo exato ou aproximado, incluindo cálculo mental.

\begin{tabular}{|c|c|c|c|}
\hline $\begin{array}{l}\text { Unidade } \\
\text { Temática }\end{array}$ & $\begin{array}{c}\text { Objeto do } \\
\text { Conhecimento }\end{array}$ & Objetivos & Estratégias Didáticas \\
\hline \multirow{5}{*}{ Números } & \multirow{5}{*}{$\begin{array}{l}\text { Problemas } \\
\text { envolvendo } \\
\text { significados da } \\
\text { adição e da } \\
\text { subtração: reunir, } \\
\text { acrescentar, } \\
\text { separar, retirar e } \\
\text { completar } \\
\text { quantidades. }\end{array}$} & $\begin{array}{l}\text { Desenvolver atitudes de } \\
\text { interação, colaboração e } \\
\text { troca de experiências em } \\
\text { grupos. }\end{array}$ & $\begin{array}{l}\text { Etapa motivacional } \mathbf{E}(\mathbf{0}) \text { : } \\
\text { estimular os discentes, } \\
\text { durante todo o processo, } \\
\text { por meio de diálogos que } \\
\text { valorizem a construção da } \\
\text { autoconfiança criando um } \\
\text { ambiente aberto e } \\
\text { acessível a todos. }\end{array}$ \\
\hline & & $\begin{array}{l}\text { Sistematizar a noção de } \\
\text { adição e subtração aos } \\
\text { conceitos de: reunir, } \\
\text { acrescentar, separar, retirar } \\
\text { e completar quantidades. }\end{array}$ & $\begin{array}{l}\text { Etapa de Formação da } \\
\text { BOA E(1): por meio da } \\
\text { orientação dada para } \\
\text { execução das tarefas, os } \\
\text { discentes precisam } \\
\text { compreendê-las e resolvê- } \\
\text { las de acordo com a } \\
\text { orientação dada. }\end{array}$ \\
\hline & & $\begin{array}{l}\text { Sistematizar, por meio dos } \\
\text { conhecimentos adquiridos, } \\
\text { situações que envolvam as } \\
\text { operações de adição e } \\
\text { subtração. }\end{array}$ & $\begin{array}{l}\text { Etapa de Formação da } \\
\text { Ação Materializada E(2): } \\
\text { nessa Etapa os discentes } \\
\text { precisam, a partir da } \\
\text { compreensão da tarefa, } \\
\text { saber fazer a ação com o } \\
\text { auxílio e/ou orientação de } \\
\text { um adulto ou dos colegas. }\end{array}$ \\
\hline & & $\begin{array}{l}\text { Desenvolver o raciocínio } \\
\text { lógico matemático e a } \\
\text { concentração. }\end{array}$ & \multirow{2}{*}{$\begin{array}{l}\text { Etapa de Formação da } \\
\text { Ação Verbal Externa } \mathbf{E}(\mathbf{3}) \text { : } \\
\text { com a execução das } \\
\text { tarefas, nessa Etapa o } \\
\text { discente precisa saber } \\
\text { fazer e explicitar-se }\end{array}$} \\
\hline & & $\begin{array}{l}\text { Identificar e diferenciar as } \\
\text { situações em que se usa as } \\
\text { operações de adição e }\end{array}$ & \\
\hline
\end{tabular}




\begin{tabular}{|l|l|l|}
\hline & subtração. & $\begin{array}{l}\text { oralmente e utilizar } \\
\text { registros escritos para as } \\
\text { respostas dadas. }\end{array}$ \\
\cline { 3 - 4 } & $\begin{array}{l}\text { Resolver situações } \\
\text { problemas que envolvam } \\
\text { as operações de adição e } \\
\text { subtração. }\end{array}$ & \\
\hline
\end{tabular}

Fonte: Elaboração dos Autores (2021)

Na elaboração da sequência didática foram propostas tarefas que apresentavam características imprescindíveis para a construção do sistema de operações das ações e de controle, centrados na ASPD com operações de adição e subtração, em concordância com os objetivos e circunstâncias do ensino. Delgado e Mendoza (2016), baseados na Teoria de Galperin, quando se referem aos processos de ensino e aprendizagem, enfatizam que estes devem trazer ações que oportunizem a automatização das reações dos discentes ante as dificuldades e o façam se reorganizar de forma racional e eficiente.

\section{Procedimentos Metodológicos}

O percurso para analisar e interpretar a aplicação da ASPD com operações de adição e subtração demandou uma metodologia que foi ao encontro dos pressupostos teóricos do estudo e propôs um processo de construção coletiva do conhecimento, no intuito de fortalecer e atender aos objetivos delineados. Por meio de uma metodologia bem definida foi traçado um direcionamento teórico e técnico aos caminhos percorridos para execução dos procedimentos. Dessa forma, considerando a importância do processo, a linha metodológica se desenvolveu por meio de uma pesquisa com abordagem de cunho qualitativo.

O enfoque qualitativo da pesquisa foi concebido a partir da variedade de características dadas por Sampieri, Callado e Lucio (2013, p. 9), dentre outras, especificam que "a pesquisa qualitativa se baseia em uma perspectiva interpretativa focada na compreensão do significado das ações dos seres vivos, especialmente dos seres humanos e suas instituições (busca interpretar o que se está apreendendo ativamente)". Para os autores, os dados qualitativos descrevem um conjunto de práticas explicativas que buscam entender o fenômeno investigado. Dessa forma, a pesquisa considerou que a metodologia estivesse estruturada de modo que se mantivesse uma relação próxima com o objeto de estudo e pudesse dar voz aos participantes.

A pesquisa foi realizada no Colégio de Aplicação (CAp/UFRR), localizado no 
campus Paricarana da Universidade Federal de Roraima, no município de Boa Vista, com 13 participantes, do $3^{\circ}$ ano, na faixa etária que variava entre 8 e 9 anos. O foco não foi apenas analisar a contribuição da ASPD para formação de habilidade na resolução de problema, mas buscar compreender os seus significados e como tais habilidades se manifestaram nos discentes participantes da pesquisa. Assim, ao conviver com a realidade dos participantes houve a precaução de estudá-la e compreendê-la para que os resultados fossem apontados.

As unidades de análises da pesquisa foram procedimentadas na perspectiva qualitativa. A análise quantitativa foi baseada nas considerações de Gatti (2004, p. 13) que afirma que "há problemas educacionais que para sua contextualização e compreensão necessitam ser qualificados através de dados quantitativos", o importante, portanto, é que, de acordo com os objetivos, seja possível saber por que se quer quantificar estabelecendose o ponto chave da investigação. Assim, a obtenção dos dados considerou os aspectos qualitativos e quantitativos de forma unificada, de modo que se constituíram em estratégias que se completaram.

$\mathrm{Na}$ pesquisa, as análises qualitativa e quantitativa foram realizadas a partir das operações de controle da ASPD, conforme critérios predeterminados, levando-se em consideração as quatro ações envolvidas, estas foram planejadas no Esquema da Base Orientadora Completa da Ação (EBOCA) da ASPD com operações de adição e subtração e organizadas na sequência didática, que permearam todo processo de ensino e aprendizagem durante a execução da pesquisa. A produção de dados considerou a verificação do desempenho dos discentes a partir dos resultados obtidos no diagnóstico inicial, nas avaliações formativa e final, considerando todas as informações registradas nas Guias de observação.

A análise da ASPD com operações de adição e subtração teve como mote a resolução de problema por meio de tarefas que envolveram tais operações e necessitou de definições que determinassem o acompanhamento do desenvolvimento das ações a partir da quantificação dos elementos que compunham as operações a serem realizadas em cada etapa formativa. A contar desse contexto, os aspectos quantitativos da pesquisa foram preestabelecidos a partir dos resultados consolidados, considerando a equivalência dos níveis alcançados a depender dos indicadores determinados para cada operação. Os dados 
foram categorizados e aferido sua frequência nas classificações para que os agrupamentos fossem identificados de acordo com as características determinadas pelos níveis alcançados, discriminando-se um do outro.

Partindo-se do fato de que as operações de controle são o acompanhamento do professor em relação ao desempenho dos discentes quanto às operações das ações, a referência para quantificação foi sempre o indicador essencial de cada operação de acordo com o nível alcançado pelos discentes: se todos os indicadores estão incorretos, será considerado nível 1; se o indicador essencial está incorreto ou parcialmente incorreto e/ ou existe pelo menos outro indicador parcialmente correto, será assinalado nível 2; se o discente tem somente correto o indicador essencial, nível 3; se o indicador essencial está correto, mas existe pelo menos outro indicador parcialmente correto, estará no nível 4; e se todos os indicadores estão corretos, indicará o nível 5.

Os critérios para análise da Formação por Etapas das Ações Mentais de Galperin seguiram o que preconiza Talízina (1988) quando define que as ações primárias são independentes e tem como propriedades principais: a forma, o caráter generalizado, o caráter assimilado e o caráter explanado. À medida em que se fez a análise do diagnóstico inicial e das avaliações formativa e final foram observados o caráter qualitativo das ações primárias e utilizou-se em cada etapa os termos e conceitos de acordo com as características apresentadas no Quadro 3. Tais características exprimem o desenvolvimento da etapa mental, de acordo com a categoria elencada, associadas às respostas dadas pelos discentes nas tarefas propostas durante a investigação.

Quadro 3: Características primárias das ações

\begin{tabular}{|c|c|c|c|c|c|}
\hline Categorias & $\mathbf{1}^{\mathbf{a}}$ Etapa & $\mathbf{2}^{\mathbf{a}}$ Etapa & $\mathbf{3}^{\mathbf{a}}$ Etapa & $\mathbf{4}^{\mathbf{a}}$ Etapa & $\mathbf{5}^{\mathbf{a}}$ Etapa \\
\hline Forma & Material & Material & $\begin{array}{c}\text { Verbal } \\
\text { Externa }\end{array}$ & Interna & Interna \\
\hline Generalização & $\begin{array}{c}\text { Não } \\
\text { generalizado }\end{array}$ & $\begin{array}{c}\text { Pouco } \\
\text { generalizado }\end{array}$ & Generalizado & Generalizado & Generalizado \\
\hline Independência & Detalhado & Detalhado & Detalhado & $\begin{array}{c}\text { Pouco } \\
\text { detalhado }\end{array}$ & Reduzida \\
\hline Assimilado & $\begin{array}{c}\text { Pouco } \\
\text { Consciente }\end{array}$ & $\begin{array}{c}\text { Pouco } \\
\text { Consciente }\end{array}$ & $\begin{array}{c}\text { Semi- } \\
\text { Consciente } \\
\text { independentente }\end{array}$ & Independente \\
\hline
\end{tabular}

Fonte: Adaptado de Souza (2020) 
A produção de dados para a pesquisa alicerçou-se a partir dos procedimentos de coleta, que utilizou o diagnóstico inicial, as avaliações formativas, a avaliação final e as guias de observação e análise da realização das ações pelos discentes.

As tarefas utilizadas incialmente, durante o diagnóstico, foram elaboradas e aplicadas antes de qualquer intervenção, com o objetivo de analisar os conhecimentos dos discentes. Nessas tarefas estavam presentes situações-problema contextualizadas envolvendo as operações de adição e subtração. Posterior ao teste diagnóstico foi elaborada a base de orientações e as avaliações formativas — também com situaçõesproblema contextualizadas de adição e subtração —, com o objetivo de acompanhar o desenvolvimento discente e analisar a construção de conceitos matemáticos. A avaliação final foi aplicada com objetivo de verificar e comparar os conhecimentos discentes antes e após as orientações e a utilização da ASPD. Durante todo o processo, os discentes também foram acompanhados via guia de observação, onde foram realizadas anotações pertinentes ao desenvolvimento e à aprendizagem.

Dessa forma, os instrumentos foram aplicados em concordância com as operações definidas no EBOCA da ASPD e com o planejamento da sequência didática. Dessa maneira, a coleta para obtenção de dados trouxe subsídios que foram adicionados ao valor da pesquisa para o campo investigado, no que se refere aos objetivos determinados evidenciando-se as conquistas alcançadas, suas limitações, considerações e reconsiderações.

\section{Análises e discussão de resultados}

O diagnóstico inicial tencionou possibilitar conhecer informações dentro de um contexto de aprendizagem, relação com os conteúdos matemáticos e novos saberes a partir de uma construção paralela de ações e operações. Em sua função pedagógica o instrumento buscou subsídios para conhecer as especificidades dos discentes de modo que houvesse possibilidades de interação, como uma forma de contribuição para direcionar o planejamento nos processos de ensino e de aprendizagem. Os dados solicitados no diagnóstico consistiram na percepção da formação dos conceitos aditivos e subtrativos no que se refere a reunir, separar, retirar e/ ou comparar quantidades. Dessa maneira, pretendeu-se realizar uma análise descritiva da aprendizagem dos discentes e 
perceber as características coletivas e individuais da turma.

Composto por cinco tarefas, o diagnóstico inicial envolveu as quatro ações da ASPD, sendo elas: $1^{\mathrm{a}}$ ação - Formular o problema discente; $2^{\mathrm{a}}$ ação - Construir o núcleo conceitual ou procedimental; $3^{\mathrm{a}}$ ação — Solucionar o problema discente; e $4^{\mathrm{a}}$ ação - Analisar a solução. Objetivou diagnosticar o nível de partida dos discentes em relação às habilidades na resolução de problema com operações de adição e subtração e, ao mesmo tempo, ajustar o planejamento das aulas de acordo com as necessidades de aprendizagem. As questões propostas nas situações-problema tiveram relação com o contexto próximo às vivenciadas no cotidiano dos discentes, de modo que não fossem tão fáceis a ponto de não estimular a aprendizagem, nem tão difíceis que se tornasse impossível realizá-las. No Quadro 4 são apresentadas as tarefas.

Quadro 4: Diagnóstico inicial

Tarefa 1 - No estacionamento do Colégio de Aplicação havia 35 carros. Chegaram mais 9. Quantos carros ficaram no estacionamento?

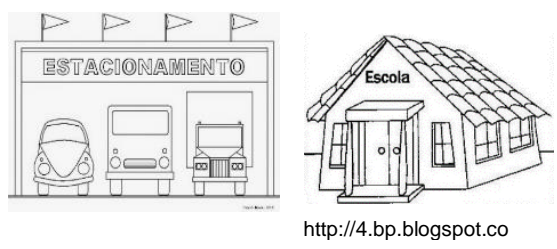

a) No problema acima você já sabe que havia 35 carros e que chegaram mais 9 . Escreva o que o problema pede para você descobrir.

b) Escreva como você faria para encontrar o resultado.

c) De que outra forma você pode encontrar o mesmo o resultado?

Tarefa 2 - Fábio deu 22 figurinhas para João e ainda ficou com 15. Quantas figurinhas Fábio tinha anteriormente?

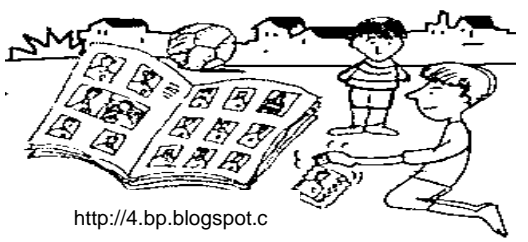

a) Escreva como você faria para encontrar o resultado. Se caso precisar você também pode utilizar desenhos.

Tarefa $3-\mathrm{O} 3^{\circ}$ Ano tem 25 alunos. 12 alunos não acessaram o SIGAA. Qual é o total de alunos que acessaram o SIGAA?

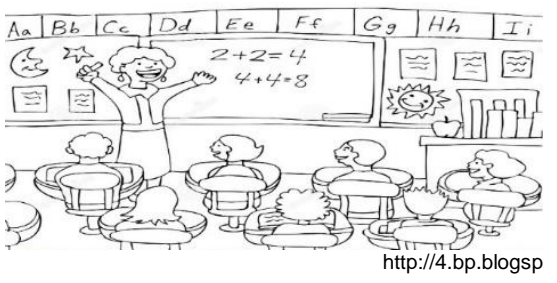

Agora responda:

a) Quantos alunos tem no $3^{\circ}$ Ano?

b) Quantos alunos não acessaram o SIGAA?

c) O que você deve fazer para encontrar o resultado? Escreva explicando:

Tarefa 4 - Roberta fez 32 pontos no jogo de basquete. Paula fez 24 pontos. Quantos pontos Roberta fez a mais que Paula? 


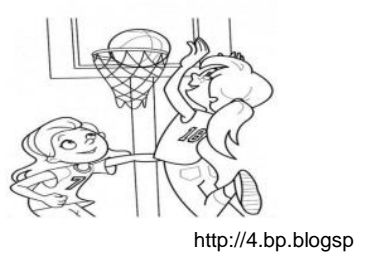

a) Quanto pontos Roberta fez a mais que Paula?

b) O que você deve fazer para encontrar o resultado?

Tarefa 5 - Numa estante da biblioteca do Colégio de Aplicação havia 120 livros. Retiraram 48 para doação e depois colocaram mais 23. Quantos livros ficaram?
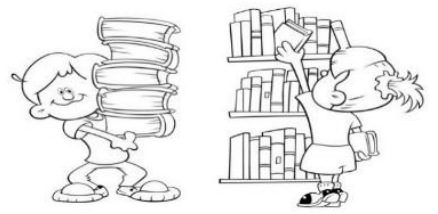

http://4.bp.blogsp a) O que você deve fazer para encontrar o resultado?

b) Escreva como você faria para encontrar a resposta para esse problema:

Fonte: Elaboração dos Autores (2021)

Para tanto, com as análises concluídas a partir dos resultados obtidos com as respostas das tarefas propostas, foi possível ter um diagnóstico inicial sobre o nível de partida do discentes quanto ao conhecimento referente aos conceitos de adição e subtração indicados em cada tarefa.

A partir da sistematização dos dados coletados e realizadas as análises quantitativas e qualitativas, foi possível reconhecer as características primárias das ações executadas pelos discentes. Nesta perspectiva, as médias das ações das tarefas apresentaram um panorama geral dos resultados dos discentes, que apontaram desempenho de $100 \%$ na execução das operações da $1^{\text {a }}$ ação: formular o problema discente e da $2^{\mathrm{a}}$ ação: construir o núcleo conceitual e procedimental; e $62 \%$ na execução da $3^{\text {a }}$ ação: solucionar o problema discente e da $4^{\text {a }}$ ação: analisar a solução. Dados no Gráfico 1.

Quanto às características primárias das ações, os discentes apresentaram desenvolvimento da etapa mental, de acordo com a categoria elencada e associada às respostas dadas nas tarefas. Os grupos de discentes ficaram assim distribuídos nas seguintes Etapas: $1^{a}$ Etapa: as ações foram executadas de forma materializada, não generalizada, com explanação detalhada, independência compartilhada e pouco consciente (D1, D6 e D11); $2^{a}$ Etapa: as ações foram executadas de forma materializada, pouco generalizada, com explanação detalhada, independência compartilhada e pouco consciente (D8 e D10); $3^{a}$ Etapa: as ações foram executadas de forma verbal externa, 
generalizada, com explanação detalhada, semi-independente e consciente (D2, D3, D4, D5, D7, D9, D12 e D13).

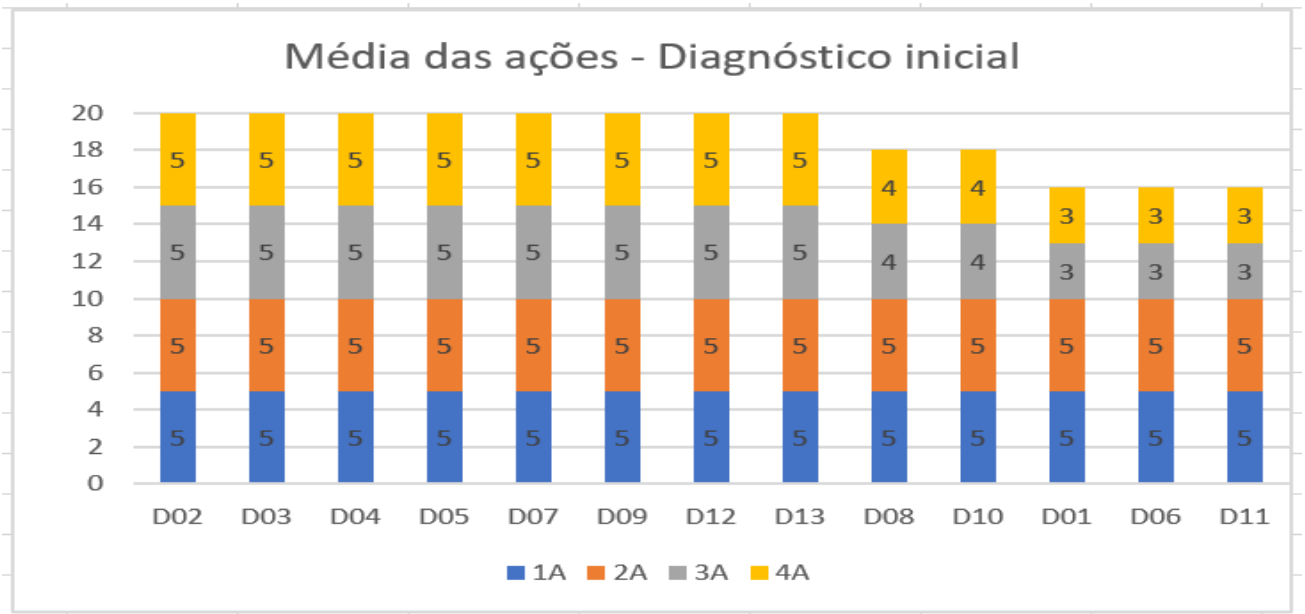

Gráfico 1: Média das ações do Diagnóstico inicial (Dados da Pesquisa, 2021)

Com os resultados consolidados da turma foi possível analisar o que cada um sabe e quais caminhos ainda necessitam trilhar. Houve ações e operações que causaram divergências na sua solução, sendo necessário trabalhar com alguns discentes de forma prioritária e com os demais, que resolvem bem determinadas questões, foi elementar pensar em tarefas mais aprofundadas elevando o nível do desafio. Surgiram tarefas em que os discentes utilizaram a adição ao invés da subtração e, também, representações por meio de riscos e desenhos. Portanto, é importante evidenciar que a escolha das estratégias mais adequada para resolver uma situação-problema demanda ter clareza com as ações e operações a serem realizadas.

A avaliação formativa aplicada teve como objetivo principal constatar se os discentes conseguiam construir conhecimento a partir dos estudos e das orientações dadas. Foi um instrumento que trouxe o controle e a identificação da evolução do aprendizado, analisando a apreensão das ações e operações da ASPD. Assim, a avaliação formativa foi composta de duas tarefas que envolveu a formação dos conceitos aditivos e subtrativos no que se refere a reunir, separar, retirar e/ ou comparar quantidades. A Figura 1 indica as tarefas propostas.

Quanto à apropriação da ação pelos discentes na realização das operações das tarefas, estas ocorreram de duas formas: Materializada, quando o primeiro grupo de discentes (D1, D4, D6, D8, D10 eD11) necessitou de apoio de recurso materializado para compreender e buscar os caminhos para solução, indicou características de pouca 
generalização, pois necessitava que o contexto da ação fosse ainda o mais próximo possível da sua realidade; e Verbal externa, quando o segundo grupo de discentes (D2, D3, D5, D7, D9, D12 e D13) externalizou a resolução das operações das ações de forma oral ou escrita sem a necessidade de recurso materializado, apresentou características de generalização completa, pois conseguiu identificar as ações essenciais das operações de adição e subtração em diversos contextos.

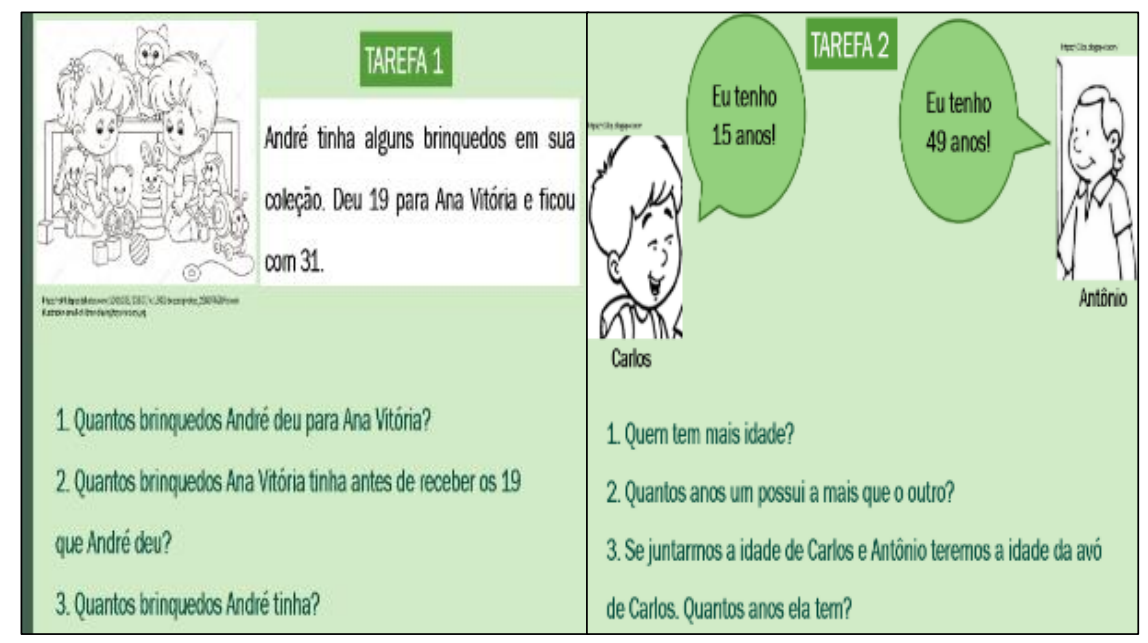

Figura 1: Avaliação formativa (Elaboração dos Autores, 2021)

Com relação ao caráter de explanação das ações, os dois grupos mantiveram as características de explanar com detalhes todas as operações realizadas, com registros escritos ou orais. O que diferencia os grupos são o grau de independência de cada um deles, enquanto o primeiro grupo realizou as operações com a ajuda de um adulto, ou ainda, com base na experiência de outros colegas, com independência compartilhada e pouco consciente, ou seja, não conseguiu explicar totalmente como executou as operações e nem corrigiu os erros; o segundo grupo se apresentou semi-independente necessitando de ajuda para compreender ou executar as operações casualmente, conseguindo explicar como realizou as operações e com autonomia para identificar os erros.

A avaliação final teve o objetivo de verificar os resultados da aprendizagem dos discentes, a partir dos conceitos que foram estudados, para que se compreendesse a trajetória do processo de ensino e aprendizagem compatível com a teoria e a prática formativa utilizada, e não somente levantar indícios de acertos e erros. A Figura 2 retrata a tarefa indicada. 


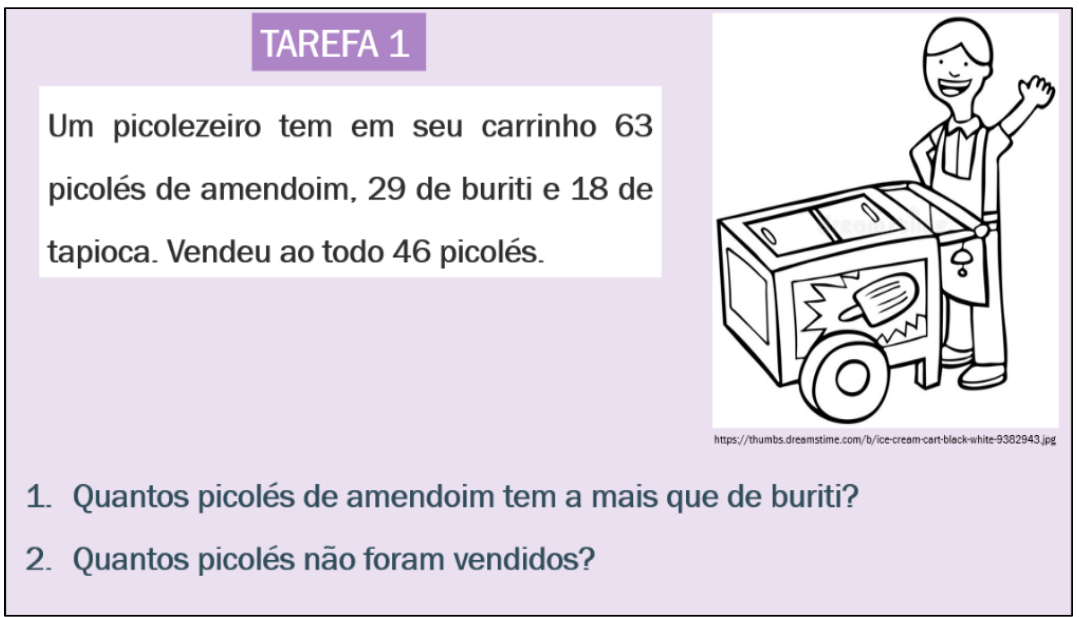

Figura 2: Avaliação final (Elaboração dos Autores, 2021)

Ao se observar os dados apresentados na análise dos resultados avaliação final, Gráfico 2, percebeu-se que estes apresentaram-se de forma diferenciada dos analisados após a avaliação formativa, mostrando uma evolução na concepção dos conceitos por parte dos discentes. Percebeu-se servindo como ferramenta para refletir as causas das dificuldades e definir as ações para diminuí-las ou, ainda, aprimorar a construção dos saberes relativos aos conceitos aditivos e subtrativos, oportunizando uma visão mais ampla no acompanhamento dos avanços em relação às operações. Os conceitos de adição e subtração estão associados às construções que se aprende desde os primeiros anos de vida com as experiências concebidas e estimuladas no meio em que se vive. O importante é que esses conceitos devem levar os discentes a não simplesmente realizar cálculos numéricos, mas saber reconhecer onde a situação problêmica está inserida, para poder dar sentido a sua utilidade e fazer o discente progredir de um conceito inicial para um outro vinculado a situações convencionais.

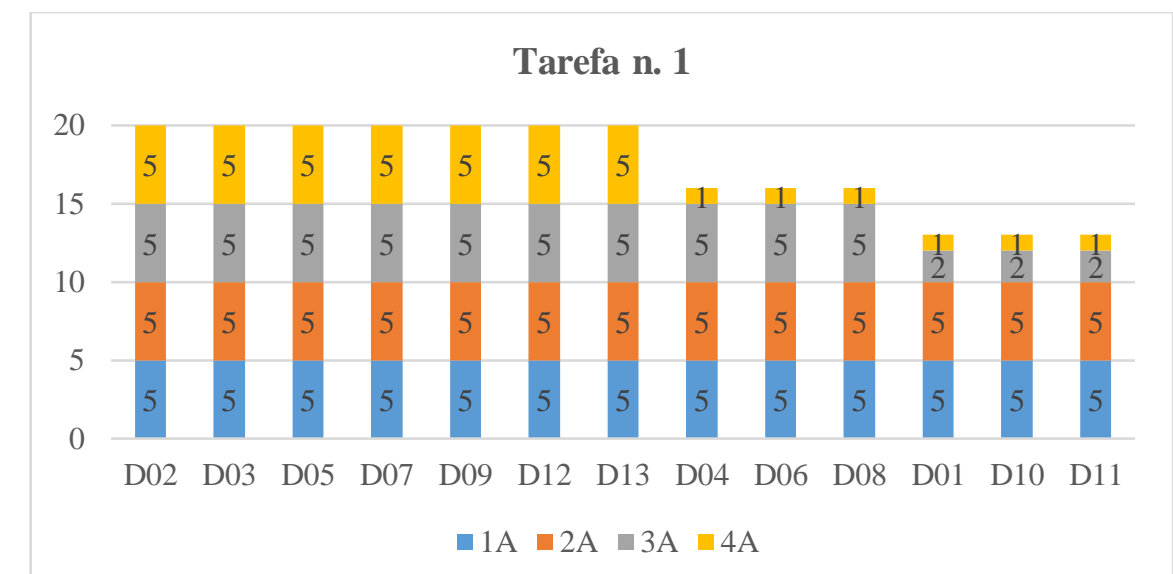

Gráfico 2: Resultado dos discentes na Avaliação final (Elaboração dos Autores, 2021) 
Na tarefa da avaliação final os resultados de desempenho dos discentes apontaram índices que evidenciaram a capacidade de eles terem desenvolvido estratégias de resolução e de expansão dos seus conhecimentos, ocasionando avanços no processo de aprendizagem. As operações de adição e subtração estavam associadas com diversos conceitos cada um relacionado a uma ideia de forma diferente, pois, distingui-los facilitou a percepção dos conhecimentos que foram solidificados, interação imprescindível durante o processo de construção e reconstrução da aprendizagem. Os resultados analisados indicaram que diante de uma situação-problema, estes mostraram, por meio de suas respostas, o quanto é importante as tarefas de resolução de problema nas aulas de Matemática e, ainda, como conseguiram desenvolver os conceitos essenciais para os cálculos operatórios refletidos não apenas em algoritmos, mas em processos de aprendizagem.

\section{Formação por Etapas das Ações Mentais}

A ideia principal da Teoria de Galperin é que as ações mentais são ações objetivas e se realizam por meio de tarefas com apoio de recursos externos ou com suas representações, passando por várias etapas até chegar ao plano mental. O processo de internalização dos conceitos científicos, nessa Teoria, está diretamente ligado à constituição destes no processo de aprendizagem, sendo a base para a formação das ações mentais. As Etapas de Formação das Ações Mentais são cinco: Etapa (0) motivacional, $1^{\text {a }}$ Etapa - construção da BOA, $2^{\text {a }}$ Etapa - Material ou Materializada, $3^{\text {a }}$ Etapa Verbal Externa, $4^{\text {a }}$ Etapa - Verbal externa para si, e $5^{\text {a }}$ Etapa - Linguagem interna, que foram as etapas observadas, orientadas e controladas durante todo o desenvolvimento da pesquisa.

A aplicação da Teoria de Galperin na resolução de problema com operações de adição e subtração subsidiou os processos de ensino e de aprendizagem dos discentes de forma sistêmica. A partir desse fundamento a ASPD trouxe contribuições relevantes para o desenvolvimento de habilidades na resolução de problema matemático nos discentes de $3^{\circ}$ ano e evidenciou as etapas mentais que eles chegaram após a sua aplicação. A ASPD, como atividade orientada, organizada e conduzida pelo professor, de modo a tornar o discente como participante ativo da sua aprendizagem, foi um componente impulsionador para conduzir todo o processo com a qualidade desejada. Portanto, com o 
desenvolvimento de todas as tarefas propostas na sequência didática estabeleceu-se um caminho para a formação planejada dos discentes e, após todas as análises dos resultados do desempenho e observações realizadas, acredita-se que é possível disponibilizar tarefas orientadas para organizar os procedimentos dos discentes na formação das etapas mentais.

A turma de discentes, após passarem pelas Etapas Motivacional e formação da BOA, desenvolveu a aprendizagem de maneira ativa e evolutiva, conforme explicitado nos resultados a seguir.

O primeiro grupo, composto por três discentes (D1, D10 e D11), apresentou características referentes à $2^{\mathrm{a}}$ Etapa de Formação mental, a Material ou Materializada. Esses discentes realizaram as orientações de forma materializada, pois ainda necessitavam contar todos os numerais e para isso utilizaram os dedos ou rabiscos para efetuar a contagem. Esse recurso é a maneira mais rápida que os discentes, nessa Etapa, encontraram para contar; quanto à compreensão das ações e operações da ASPD procederam de forma não generalizada - em alguns momentos pouco generalizada pois tiveram dificuldades em realizar as operações indicadas incluindo o elemento essencial; conseguiram verbalizar e/ou registrar as operações que seriam processadas, muito embora o fizessem com uma independência compartilhada, visto que necessitavam de orientações frequentes para compreender ou realizar as tarefas, e ainda, para algumas operações tinham pouca consciência, pois não conseguiam explicar como se deu a operação e nem se haviam erros quanto aos resultados.

O segundo grupo foi constituído por dez discentes (D2, D3, D4, D5, D6, D7, D8, D9, D12 e D13) que evidenciaram características da $3^{\text {a }}$ Etapa de Formação mental, realizando as ações de forma verbal externa, externalizando de forma oral e escrita os caminhos percorridos para a resolução das operações e generalizando ao identificar as ações essenciais, mas ainda com necessidades de verbalizar ou registrar todas as operações que executaram. Nessa Etapa esse grupo de discentes executou as ações de forma semi-independente solicitando ajuda casualmente do professor, conseguiu explicar a execução das operações e teve autonomia para perceber os erros.

Dado os resultados expostos e analisados, acredita-se que os discentes resolveram as tarefas propostas a partir da Atividade de Situação-Problema Discente com operações de adição e subtração de maneira efetiva, respeitando-se as Etapas de Formação Mental 
em que se encontravam e considerando-se a heterogeneidade dos discentes como um desenvolvimento produtivo e qualitativo definido nos objetivos dos processos de ensino e de aprendizagem.

\section{Considerações Finais}

Ao iniciar este trabalho de pesquisa constatou-se a necessidade de desenvolver aulas de Matemática voltadas para a resolução de problema, ancoradas no Ensino Problematizador de Majmutov, na Direção da Atividade de Estudo de Talízina e na teoria de Formação por Etapas das Ações Mentais de Galperin, que estabeleceram a produção de conhecimentos levando-se em consideração o contexto de aprendizagem dos discentes. Uma situação-problema é uma tarefa que demanda a utilização de estratégias de solução, associa às vivências reais dos discentes (conhecido) e estimula-os a produzir algo novo (desconhecido), apoiada na organização e planejamento do professor, sendo de suma importância os estudos voltados para a aplicação da ASPD para formação de habilidade na resolução de problema com operações de adição e subtração nos discentes de $3^{\circ}$ ano.

Em face do exposto, o objetivo de analisar as contribuições da Atividade de Situações Problema Discente fundamentada na teoria de Galperin (1979), Talízina (1988) e Majmutov (1983) para formação de habilidade na resolução de problema com operações de adição e subtração nos discentes de $3^{\circ}$ ano do Ensino Fundamental do CAp/UFRR, evidenciou-se de forma efetiva, pois a investigação analisou os caminhos viáveis para execução da ASPD como subsídios para um ensino problematizador por meio do objeto de estudo proposto, com resultados que ampliaram a aprendizagem dos discentes. Assim, foi possível diagnosticar o nível de partida dos discentes em relação às habilidades na resolução de problema, confirmando-se o nível de domínio dos conceitos aditivos e/ou subtrativos desenvolvidos a partir de uma situação-problema, necessários para novas aprendizagens. Contribuiu também para apontar algumas dificuldades iniciais que os discentes tiveram na definição de estratégias para chegar até a solução.

A verificação das contribuições do Esquema da Base Orientadora Completa da Ação da Atividade de Situações Problema Discente para a construção de uma sequência didática no desenvolvimento de habilidades na resolução de problema, estiveram centradas no planejamento do professor com a construção do EBOCA da ASPD e com a 
organização da sequência didática para o estabelecimento de tarefas sistemáticas de acompanhamento da evolução da aprendizagem dos discentes, que foram: o diagnóstico inicial, as avaliações formativa e final e o estímulo para que os discentes organizassem suas estratégias de estudo, para que a partir do que eles já sabiam conseguissem traçar uma trajetória evolutiva por meio da resolução de problema.

Com o desenvolvimento da pesquisa determinou-se em que etapa mental os discentes chegaram após a aplicação da sequência didática, sendo concluída essa verificação ao se destacar as etapas a que chegaram cada grupo de discentes da turma, pois seguindo a concepção da teoria de Galperin ao final de um ciclo de aprendizagem, deve-se construir uma ação mental interna, generalizada, reduzida, independente e automatizada. Assim, a aprendizagem não é finita nos conceitos aditivos e subtrativos elaborados, mas, sim, na possibilidade de os discentes agirem mentalmente com ele, manifestando se houve a internalização, conscientização e operacionalização do conhecimento adquirido.

Ao longo do desenvolvimento desta pesquisa identificaram-se situações relacionadas ao ensino da Matemática que merecem destaque, quando estas se referem ao ensino a partir da resolução de problema e em uma teoria de ensino que fundamenta e direciona o planejamento do professor. A partir das análises das contribuições da Atividade de Situações Problema Discente com operações de adição e subtração constatase que é necessário direcionar os processos de ensino e de aprendizagem para o avanço na consolidação das ações de solucionar o problema discente e analisar a solução. Com isso, acompanhar a aprendizagem dos discentes orientando-os para a realização de ações e operações com base no EBOCA da ASPD e na sequência didática poderá trazer novas práticas metodológicas que envolvam a participação ativa do discente na construção do aprendizado, em busca de sua autonomia.

\section{Referências}

BRASIL. Ministério da Educação. Secretaria da Educação Básica. Base Nacional Comum Curricular: Educação Infantil e Ensino Fundamental. Brasília: MEC/SEB, 2017.

BUENO, Simone; ALENCAR, Edvonete Souza de; MILLONES, Teresa Sofía Oviedo. Reflexões e desafios da resolução de problemas nas aulas de Matemática: um ensaio teórico. Educação Matemática Debate, Montes Claro, v. 1, n. 1, p. 9-27, jan/abr. 2017.

DELGADO, Oscar Tintorer; MENDOZA, Héctor José Garcia. Evolução da Teoria 
Histórico-Cultural de Vygotsky à Teoria de Formação por Etapas das Ações Mentais de Galperin. In: GHEDIN, Evandro; PETERNELLA, Alessandra. (Org.). Teorias psicológicas e suas implicações à Educação em Ciências. Boa Vista: EdUFRR, 2016, p. 355-381.

FEITOSA, Soraya de Araújo. A Atividade de Situações Problema como estratégia didática no Tratamento da Informação no $6^{\circ}$ ano do Ensino Fundamental a partir da Teoria de Galperin. 2014. 148f. Dissertação (Mestrado em Ensino de Ciências) Universidade Estadual de Roraima. Boa Vista.

GALPERIN, Petr Yakovlevich. Introduccíon a la Psicologia: um enfoque dialéctico. Traducción de Angela Bustamante. Madrid: Pablo del Río Editor, 1979.

GATTI, Bernadete Angelina. Estudos quantitativos em Educação. Educação e Pesquisa. São Paulo, v. 30, n. 1, p. 11-30, jan./abr. 2004.

GONÇALVES, Paulo Gonçalo Farias; NÚÑEZ, Isauro Beltran. A Teoria de P. Ya. Galperin nas pesquisas em Educação Matemática. Educação Matemática Debate, Montes Claro, v. 1, n. 3, p. 277-295, set/dez. 2017.

LEONTIEV, Alexis Nikolaevich. Actividad, conciencia, personalidad. Buenos Aires: Ediciones Ciencias del Hombre, 1978.

MAJMUTOV, Mirza Ismailovich. La Enseñanza Problémica. Habana: Pueblo y Revolución, 1983.

MENDOZA, Héctor José García. Estudio del efecto del sistema de acciones en el proceso de aprendizaje en los alumnos en la actividad de situaciones problema en Matemática, en la asignatura de Álgebra Lineal, en el contexto de la Facultad Actual de la Amazonia. 2009. 269f. Teses (Doctorado em Educação) — Facultad de Humanidad y Ciencia en la Educación. Universidad de Jaén. Jaén.

MENDOZA, Héctor José García; DELGADO, Oscar Tintorer. A contribuição do ensino problematizador de Majmutov na formação por etapas das ações mentais de Galperin. Obutchénie, Uberlândia, v. 2, n. 1, p. 166-192, jan./abr. 2018.

MENDOZA, Héctor José García; DELGADO, Oscar Tintorer. Proposta de um Esquema da Base Orientadora Completa da Ação da Atividade de Situações Problema Discente. Obutchénie, v. 4, n. 1, p. 180-200, ago. 2020.

NÚÑEZ, Isauro Beltran; RAMALHO, Betania Leite. A teoria da formação planejada das Ações Mentas e dos conceitos de P. Ya. Galperin: contribuições para a Didática Desenvolvimental. Obutchénie, Uberlândia, v. 1, n. 1, p. 70-97, jan./abr. 2017.

SAMPIERI, Roberto Hernández; CALLADO, Carlos Fernández; LUCIO, Maria del Pilar Baptista. Metodologia de Pesquisa. Tradução de Daisy Vaz de Moraes. 5. Ed. Porto Alegre, 2013.

SOUZA, Gilmara Batista de. A Atividade de Situações Problema Discente na 
aprendizagem de adição e subtração com operações com números naturais fundamentada em Galperin e Majmutov nos estudantes de $1^{\circ}$ ano do Ensino Fundamental na Escola Municipal Jael da Silva Barradas. 2020. 259f. Dissertação (Mestrado em Ensino de Ciências) - Universidade Estadual de Roraima. Boa Vista.

TALÍZINA, Nina Fiódorovna. La teoría de la actividad aplicada a la enseñanza. Benemérita Universidad Autónoma de Pueblo: México, 2009.

TALÍZINA, Nina Fiódorovna. Psicologia de la Enseñanza. Moscu: Progreso, 1988.

VAN DE WALLE, John Arthur. Matemática no Ensino Fundamental: formação de professores e aplicação em sala de aula. Tradução de Paulo Henrique Colonese. 6. ed. Porto Alegre: Penso, 2009.

VYGOTSKY, Lev Semionovitch. A formação social da mente: o desenvolvimento dos processos psicológicos superiores. Tradução de José Cipolla Neto, Luís Silveira Menna Barreto e Solange Castro Afeche. 6. ed. São Paulo: Martins Fontes, 2003. 